\title{
B-type natriuretic peptide in patients with asymptomatic severe aortic stenosis
}

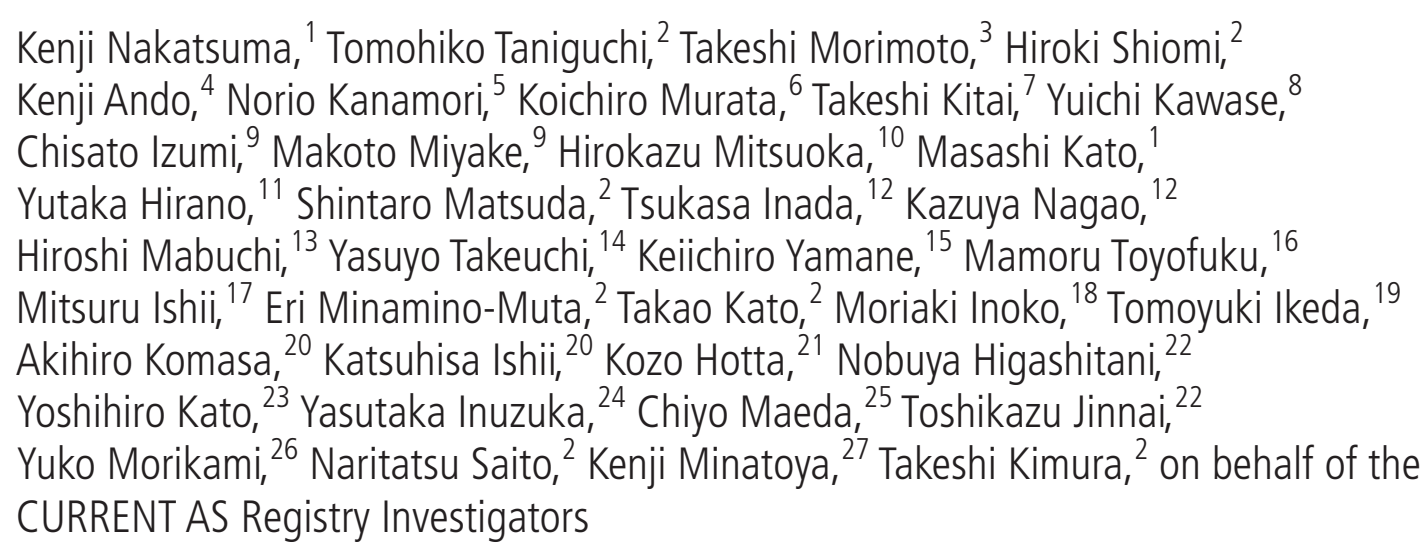

- Additional material is published online only. To view, please visit the journal online (http://dx.doi.org/10.1136/ heartjnl-2018-313746).

For numbered affiliations see end of article.

Correspondence to Professor Takeshi Kimura, Department of Cardiovascular Medicine, Kyoto University Graduate School of Medicine, Kyoto 606-8507, Japan; taketaka@kuhp.kyoto-u.ac.jp

Received 15 June 2018 Revised 4 September 2018 Accepted 6 September 2018 Published Online First 7 December 2018

\section{Linked}

- http://dx.doi.org/10.1136/ heartjnl-2018-314122

Check for updates

(c) Author(s) (or their employer(s)) 2019. No commercial re-use. See rights and permissions. Published by BMJ.

To cite: Nakatsuma $\mathrm{K}$, Taniguchi T, Morimoto T, et al. Heart 2019;105:384-390.

\section{ABSTRACT}

Objectives We sought to evaluate the prognostic impact of the B-type natriuretic peptide (BNP) levels in patients with asymptomatic severe aortic stenosis (AS), who were not referred for aortic valve replacement (AVR).

Methods We used data from a Japanese multicentre registry, the Contemporary outcomes after sURgery and medical tREatmeNT in patients with severe Aortic Stenosis Registry, which enrolled 3815 consecutive patients with severe AS. Of those, 387 asymptomatic patients who were not referred for AVR without left ventricular dysfunction and very severe AS were subdivided into four groups based on their BNP levels (BNP $<100 \mathrm{pg} / \mathrm{mL}, \mathrm{n}=201 ; 100 \leq \mathrm{BNP}<200 \mathrm{pg} / \mathrm{mL}, \mathrm{n}=94$; $200 \leq B N P<300 \mathrm{pg} / \mathrm{mL}, \mathrm{n}=42$ and $\mathrm{BNP}>300 \mathrm{pg} / \mathrm{mL}$, $\mathrm{n}=50$ ).

Results The cumulative 5-year incidence of AS-related events (aortic valve-related death or heart failure hospitalisation) was incrementally higher with increasing BNP level (14.2\%, 29.6\%, 46.3\% and 47.0\%, $p<0.001)$. After adjusting for confounders, the risk for AS-related events was incrementally greater with increasing BNP levels (HR: 1.97, 95\% Cl: 0.97 to 3.98, $p=0.06$; HR: 3.59, 95\% Cl: 1.55 to $8.32, p=0.03$ and HR: 7.38 , $95 \% \mathrm{Cl}: 3.21$ to $16.9, \mathrm{p}<0.001$, respectively). Notably, asymptomatic patients with BNPlevels of $<100 \mathrm{pg} / \mathrm{mL}$ had an event rate of only $2.1 \%$ at 1 year.

Conclusions Increased BNP level was associated with a higher risk for AS-related adverse events in patients with asymptomatic severe AS with normal left ventricular ejection fraction who were not referred for AVR. Asymptomatic patients with BNP levels of $<100 \mathrm{pg} /$ $\mathrm{mL}$ had relatively low event rate, who might be safely followed with watchful waiting strategy.

Trail registration number UMIN000012140.

\section{INTRODUCTION}

Aortic stenosis (AS) is the most common valvular heart disease in elderly patients, who represent a growing population in high-income countries. ${ }^{1}$ In both the current American and European guidelines, the presence of AS-related symptoms is the only class 1 indication for aortic valve replacement (AVR) surgery for severe AS. ${ }^{23}$ However, it is sometimes challenging to distinguish non-specific symptoms, such as fatigue and dyspnoea on exertion, from true AS-related symptoms in elderly patients. ${ }^{4}$ Furthermore, detecting mild AS-related symptoms can be difficult, particularly when the patients have limited daily life activities. Therefore, it is important to identify objective biomarkers other than AS-related symptoms that could be used to stratify the risk for AS-related adverse events in patients with severe AS. B-type natriuretic peptide (BNP), which is released from the myocardium during increased wall stress, for example, due to volume or pressure overload, is an established biomarker in the management of patients with heart failure (HF) ${ }^{45}$ In a previous study (and the current European guidelines for HF), a BNP level of $<100 \mathrm{pg} /$ $\mathrm{mL}$ was reported to be less likely to be associated with a diagnosis of congestive HF in patients with acute dyspnoea. ${ }^{5} 6$ In patients with AS, multiple studies have demonstrated that strong relationships exist between the BNP level and symptom development, ${ }^{78}$ left ventricular (LV) hypertrophy, ${ }^{9} \mathrm{LV}$ function, ${ }^{10}$ the severity of $\mathrm{AS}^{11}$ and mortality. ${ }^{11-14}$ In the recently updated European guidelines for the management of severe AS, an elevated BNP level has been added as a class 2 a (level of evidence $C$ ) recommendation of AVR surgery in patients with asymptomatic severe AS, ${ }^{3}$ while it is not mentioned in the American guidelines. ${ }^{2}$ However, there is still a paucity of data regarding risk stratification based on the BNP level in patients with asymptomatic severe AS. Therefore, we sought to evaluate the prognostic impact of the BNP levels in patients with asymptomatic severe AS who were not referred for AVR using data from a large Japanese multicentre registry of patients with severe AS. 


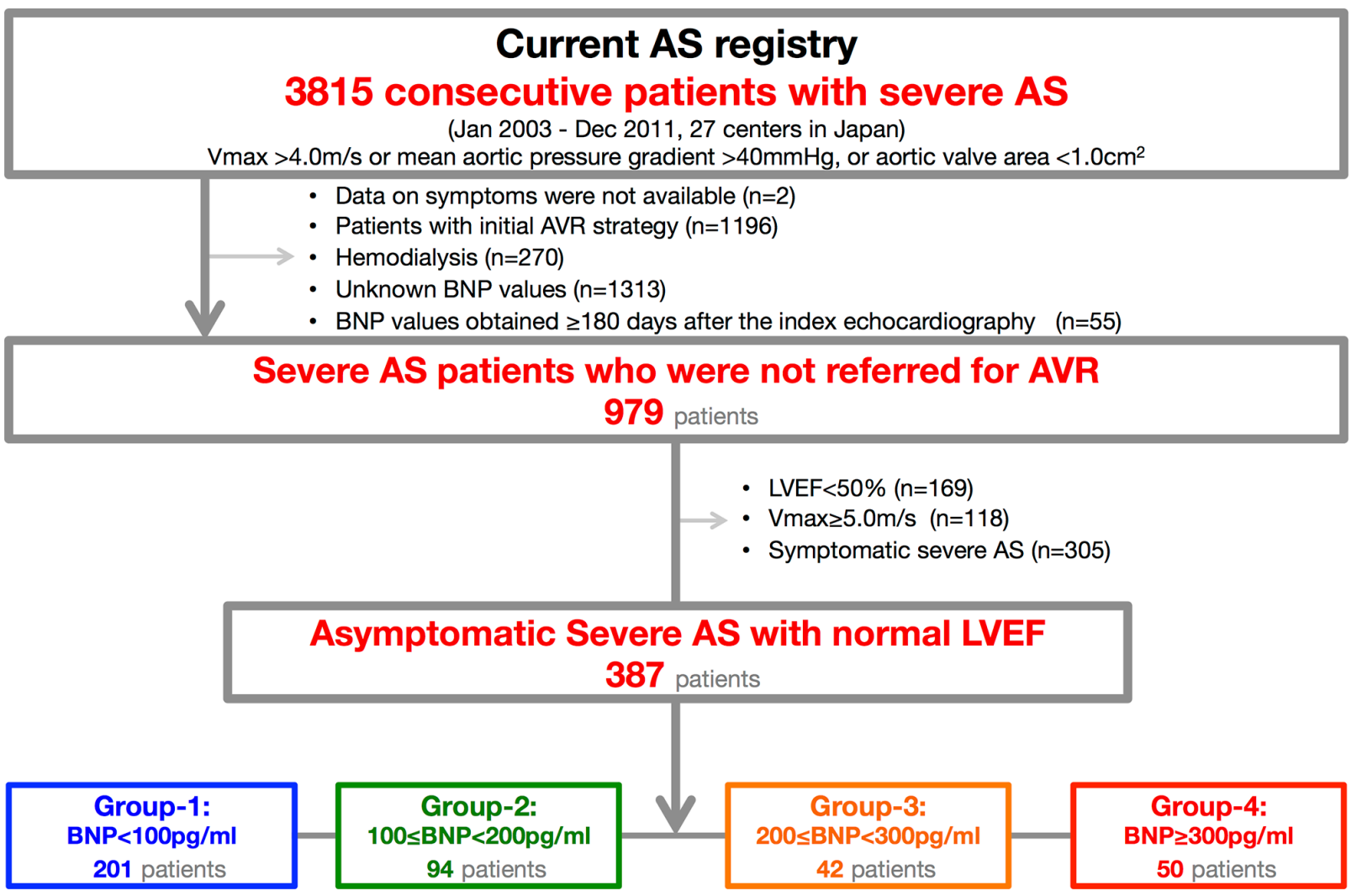

Figure 1 Study flow chart. Treatment strategies (initial AVR or watchful waiting) were selected shortly after the index echocardiography. AS, aortic stenosis; AVR, aortic valve replacement; BNP, B-type natriuretic peptide; CURRENT AS Registry, Contemporary outcomes after sURgery and medical tREatmeNT in patients with severe Aortic Stenosis Registry; LVEF, left ventricular ejection fraction; Vmax, peak aortic jet velocity.

\section{METHODS}

\section{Study population}

The Contemporary outcomes after sURgery and medical tREatmeNT in patients with severe Aortic Stenosis (CURRENT AS) Registry is a retrospective, multicentre registry that enrolled consecutive patients with severe AS who were treated at 27 centres in Japan between January 2003 and December 2011. Written informed consent from each patient was waived in this retrospective study, because we used clinical information obtained in routine clinical practice, and no patients refused to participate in the study when contacted for follow-up.

The design and the patient enrolment process of the CURRENT AS Registry have been described previously. ${ }^{3}$ Among the 3815 patients enrolled in the registry who met the definition of severe AS (a peak aortic jet velocity (Vmax) of $>4.0$ $\mathrm{m} / \mathrm{s}$, a mean aortic pressure gradient (PG) of $>40 \mathrm{~mm} \mathrm{Hg}$ or an aortic valve area (AVA) of $<1.0 \mathrm{~cm}^{2}$ ) for the first time during the study period, we excluded those patients whose symptom data were not available $(n=2)$, patients in whom AVR was selected as the initial treatment strategy after the index echocardiography $(n=1196)$, patients with haemodialysis $(n=270)$, patients whose BNP values were unknown $(n=1313)$, patients whose BNP values were obtained $\geq 180$ days after the index echocardiography $(\mathrm{n}=55)$, patients with left ventricular ejection fraction (LVEF) of $<50 \%(\mathrm{n}=169)$, Vmax values of $\geq 5.0 \mathrm{~m} / \mathrm{s}$ $(\mathrm{n}=118)$ and symptomatic patients $(\mathrm{n}=305)$. Therefore, the current study population consisted of 387 patients with severe AS who were not referred for AVR after the index echocardiography, and in whom BNP values were obtained $<180$ days after the index echocardiography (figure 1). The study patients were subdivided into four groups based on their BNP levels: group
$1(\mathrm{BNP}<100 \mathrm{pg} / \mathrm{mL}, \mathrm{n}=201)$, group $2(100 \leq \mathrm{BNP}<200 \mathrm{pg} / \mathrm{mL}$, $\mathrm{n}=94)$, group $3(200 \leq \mathrm{BNP}<300 \mathrm{pg} / \mathrm{mL}, \mathrm{n}=42)$ and group 4 $(\mathrm{BNP}>300 \mathrm{pg} / \mathrm{mL}, \mathrm{n}=50)$ (figure 1). We compared the baseline characteristics and 5-year clinical outcomes among the four groups.

\section{Data collection and definitions}

The baseline clinical information was collected through hospital chart and database reviews. Angina, syncope and HF symptoms, including dyspnoea, were regarded as AS-related symptoms. All patients at each participating centre underwent comprehensive two-dimensional and Doppler echocardiographic evaluations. The Vmax and mean aortic PG were calculated using the simplified Bernoulli equation. The AVA was calculated using the standard continuity equation and normalised to body surface area. ${ }^{15}$

The follow-up data were mainly collected through review of hospital charts or through contact with the patients or their relatives and/or the referring physicians asking questions about survival status, symptoms and subsequent hospitalisation.

The primary outcome measure in the present analysis was a composite of aortic valve-related death and HF hospitalisation. Causes of death were classified according to the Valve Academic Research Consortium definitions and were adjudicated by a clinical event committee (see the online supplementary appendix). ${ }^{15} 16$ Sudden death was defined as unexplained death in previously stable patients. Aortic valve-related death included aortic procedure-related death, sudden death and death due to HF that might have been related to AS. HF hospitalisation was defined as hospitalisation due to worsening HF that required intravenous drug therapy. The clinical event committee 
adjudicated the clinical events in a blinded fashion with respect to their BNP levels.

\section{Statistical analysis}

Continuous variables are presented as mean $\pm \mathrm{SD}$ or median and IQR, and categorical variables are shown as absolute values and percentages. We compared continuous variables using one-way analysis of variance or the Kruskal-Wallis test according to their distributions. We analysed categorical variables with the $\chi^{2}$ test. We used the Kaplan-Meier method to estimate the cumulative incidences of clinical events and assessed intergroup differences with the log-rank test. Proportional hazards assumptions for the risk-adjusting variables including the categorised age in quartiles were assessed on the plots of $\log$ (time) versus $\log (-\log$ (survival)) stratified by the variables, and verified to be acceptable. The risks of groups 2, 3 and 4 relative to group 1 for the clinical outcome measures were evaluated in the multivariable Cox proportional hazard models using dummy variables, and were expressed as adjusted HR and their 95\% CIs. We included four clinically relevant risk-adjusting non-cardiac variables (age, male sex, body mass index and the serum creatinine level), which were reported to affect the BNP level. ${ }^{17}$ We treated age, body mass index and the serum creatinine level as continuous variables in the Cox proportional hazards models. The centre was included as the stratification variable. The duration of follow-up period was calculated as the median follow-up duration of the surviving patients. Statistical analyses were conducted by a physician (KN) and a statistician (TM) using JMP V.10.0.2 or SAS V.9.4 (both SAS Institute, Cary, North Carolina, USA). All the statistical tests were two-tailed. We regarded $p$ values of $<0.05$ as statistically significant.

\section{RESULTS}

\section{Baseline characteristics}

The lowest BNP category was dominant in the asymptomatic patients (figure 1). As the BNP level increased from group 1 to group 4, patients became older, and more often had lower body mass index, atrial fibrillation or flutter, higher serum creatinine levels and higher surgical risk scores. Regarding the echocardiographic variables, patients with higher BNP levels more often had combined valvular disease, larger tricuspid regurgitation gradients and reduced LVEF (table 1). As compared with patients with initial AVR strategy $(\mathrm{n}=1196)$, those included in this study were older, and more often had higher surgical risk scores (see online supplementary table 1). In patients who were not referred for AVR, no formal indication for AVR was the leading cause of undergoing initial watchful waiting strategy (78\%), followed by high risk for AVR (14\%) and patient refusal for AVR (8.3\%). In patients who were managed with initial AVR strategy, symptomatic severe AS was the leading cause of undergoing AVR (76\%), followed by very severe AS (36\%) and LVEF <50\% (17\%).

\section{Clinical outcomes}

The median duration of the follow-up period among the surviving patients was 1190 (IQR: 732-1540) days. The cumulative 5-year incidence of surgical AVR or transcatheter aortic valve implantation (TAVI) did not differ across the four groups (see online supplementary figure 1 ). The cumulative 5 -year incidence of the primary outcome measure (aortic valve-related death or HF hospitalisation) was incrementally higher with increasing BNP levels (group 1: $14.2 \%$, group 2: $29.6 \%$, group 3: $46.3 \%$ and group 4: 47.0\%, $\mathrm{p}<0.001$ ) (figure 2). After adjusting for potential confounders, the risk for the primary outcome measure was incrementally greater with increasing BNP levels (HR: 1.97, 95\% CI: 0.97 to $3.98, p=0.06$; HR: $3.59,95 \%$ CI: 1.55 to 8.32 , $\mathrm{p}=0.03$ and HR: $7.38,95 \%$ CI: 3.21 to $16.9, \mathrm{p}<0.001$, respectively) (figure 3 ). The cumulative incidences of the secondary outcome measures, including all-cause mortality, cardiovascular mortality, aortic valve-related death, sudden death and HF hospitalisation among the four groups followed the same trend as the primary outcome measure (table 2 and online supplementary figure 2). Notably, asymptomatic patients with BNP levels of $<100 \mathrm{pg} / \mathrm{mL}$ had an event rate of only $2.1 \%$ at 1 year. Among the four patients with $\mathrm{BNP}<100 \mathrm{pg} / \mathrm{mL}$ having an event within 1 year, three patients had Vmax $>4.5 \mathrm{~m} / \mathrm{s}$ (see online supplementary table 2).

\section{DISCUSSION}

The main finding of the present study was that increased BNP level was associated with a higher risk for AS-related adverse events in patients with asymptomatic severe AS with normal LVEF, suggesting the role of BNP for risk stratification in patients with asymptomatic severe AS. Patients with asymptomatic severe AS with elevated BNP levels were associated with a higher risk of AS-related adverse events. Asymptomatic patients with BNP levels of $<100 \mathrm{pg} / \mathrm{mL}$ had relatively low event rate, who might be safely followed with watchful waiting strategy.

AS is most prevalent in elderly patients, while the assessment of symptomatic status can be particularly difficult in elderly patients because of their sedentary lifestyles and non-specific symptoms, such as fatigue and dyspnoea on exertion. Furthermore, the risk of elderly patients with AS for cardiovascular mortality is substantial, even when they are asymptomatic. ${ }^{4}$ Therefore, it is important to identify objective biomarkers other than AS-related symptoms that can be used to select those patients who are at higher risk for AS-related adverse events, and who should be treated with AVR or TAVI. The BNP level is an established biomarker for the management of HF. However, there are limited data regarding the risk stratification based on the BNP level in patients with asymptomatic severe AS. The findings obtained in the present study have highlighted the significant impact of BNP as a biomarker for risk stratification in patients with asymptomatic severe AS.

A few previous studies have evaluated the relationships between the BNP level and long-term clinical outcomes in patients with severe AS. Bergler-Klein et al reported that among 130 patients with severe AS $\left(\operatorname{Vmax} \geq 4.0 \mathrm{~m} / \mathrm{s}\right.$ and/or $\left.\operatorname{AVA}<1.0 \mathrm{~cm}^{2}\right)$, the patients with BNP levels of $\geq 130 \mathrm{pg} / \mathrm{mL}$ exhibited a higher incidences of symptom onset and death. ${ }^{12}$ Lim et al reported that among 70 patients with severe AS (an AVA $<1.0 \mathrm{~cm}^{2}$ ), the patients with BNP levels of $>97 \mathrm{pg} / \mathrm{mL}$ had a higher mortality rate. ${ }^{11}$ However, all of these studies were single-centre studies with its inherent limitation in terms of its applicability for clinical practice in general, because there would be differences in the modes of patient follow-up and in the operative mortality rate of AVR among centres. Furthermore, the age of the patients in these studies ranged from 70 to 74 years, which is much younger than the age range of the patients encountered in contemporary clinical practice. In the present study, which involved 387 patients with a mean age of 80 years from 27 centres, an increased BNP level was found to be clearly associated with incrementally worse long-term AS-related outcomes. Notably, the event rate for aortic valve-related death or HF hospitalisation in this study was very high among the patients with asymptomatic severe AS with BNP levels of $\geq 300 \mathrm{pg} / \mathrm{mL}$, while it was relatively low among those with BNP levels of $<100 \mathrm{pg} / \mathrm{mL}$. Currently, early AVR is 
Table 1 Baseline characteristics

\begin{tabular}{|c|c|c|c|c|c|}
\hline & \multirow{2}{*}{$\begin{array}{l}\text { Group } 1 \\
\text { BNP }<100 \mathrm{pg} / \mathrm{mL}\end{array}$} & \multirow{2}{*}{$\begin{array}{l}\text { Group } 2 \\
100 \leq B N P<200 \mathrm{pg} / \mathrm{mL}\end{array}$} & \multirow{2}{*}{$\begin{array}{l}\text { Group } 3 \\
200 \leq B N P<300 \mathrm{pg} / \mathrm{mL}\end{array}$} & \multirow{2}{*}{$\begin{array}{l}\text { Group } 4 \\
\text { BNP } \geq 300 \mathrm{pg} / \mathrm{mL}\end{array}$} & \multirow[b]{3}{*}{$P$ values } \\
\hline & & & & & \\
\hline & $(n=201)$ & $(n=94)$ & $(n=42)$ & $(n=50)$ & \\
\hline Age, years & $75.6 \pm 8.9$ & $80.0 \pm 8.4$ & $83.6 \pm 8.1$ & $83.7 \pm 8.3$ & $<0.001$ \\
\hline Age $\geq 80$ years & $71(35)$ & $47(50)$ & $33(79)$ & $37(74)$ & $<0.001$ \\
\hline Male & $78(39)$ & $40(43)$ & $15(36)$ & $19(38)$ & 0.87 \\
\hline $\mathrm{BSA}, \mathrm{m}^{2}$ & $1.50 \pm 0.18$ & $1.49 \pm 0.21$ & $1.46 \pm 0.20$ & $1.40 \pm 0.19$ & 0.03 \\
\hline Hypertension & $141(70)$ & $63(67)$ & $29(69)$ & $38(76)$ & 0.74 \\
\hline Current smoking & $11(5.5)$ & $2(2.1)$ & $2(4.8)$ & $1(2.0)$ & 0.48 \\
\hline Dyslipidemia & $92(46)$ & $33(35)$ & $15(36)$ & $18(36)$ & 0.24 \\
\hline On statin therapy & $64(32)$ & $25(27)$ & $12(29)$ & $14(28)$ & 0.81 \\
\hline Prior $\mathrm{CABG}$ & $9(4.5)$ & $6(6.4)$ & $1(2.4)$ & $1(2.0)$ & 0.58 \\
\hline Prior open heart surgery & $25(12)$ & $8(8.5)$ & $1(2.4)$ & $2(4.0)$ & 0.09 \\
\hline Prior symptomatic stroke & $20(10)$ & $18(19)$ & $11(26)$ & $14(28)$ & 0.002 \\
\hline Atrial fibrillation or flutter & $27(13)$ & $33(35)$ & $16(38)$ & $17(34)$ & $<0.001$ \\
\hline Aortic/peripheral vascular disease & $12(6.0)$ & $7(7.5)$ & $2(4.8)$ & $4(8.0)$ & 0.89 \\
\hline Serum creatinine, $\mathrm{mg} / \mathrm{dL}$ & $0.7(0.6-0.9)$ & $0.8(0.7-1.1)$ & $0.9(0.7-1.1)$ & $1.1(0.7-1.4)$ & $<0.001$ \\
\hline Anaemia & $86(43)$ & $55(59)$ & $27(64)$ & $34(68)$ & 0.001 \\
\hline $\begin{array}{l}\text { Liver cirrhosis } \\
\text { (Child-Pugh B or C) }\end{array}$ & $1(0.5)$ & $2(2.1)$ & $0(0)$ & $2(4.0)$ & 0.18 \\
\hline Malignancy currently under treatment & $8(4.0)$ & $7(7.5)$ & $5(12)$ & $4(8.0)$ & 0.21 \\
\hline Degenerative & $170(85)$ & $84(89)$ & $40(95)$ & $47(94)$ & \\
\hline Congenital & $19(9.5)$ & $5(5.3)$ & $1(2.4)$ & $1(2.0)$ & \\
\hline Rheumatic & $11(5.5)$ & $5(5.3)$ & $1(2.4)$ & $1(2.0)$ & \\
\hline Other & $1(0.5)$ & $0(0)$ & $0(0)$ & $1(2.0)$ & \\
\hline BNP, pg/mL & $49(32-68)$ & $142(122-164)$ & $244(221-267)$ & $543(384-684)$ & $<0.001$ \\
\hline \multicolumn{6}{|l|}{ Echocardiographic variables } \\
\hline Vmax, $\mathrm{m} / \mathrm{s}$ & $3.8 \pm 0.6$ & $3.8 \pm 0.7$ & $3.8 \pm 0.7$ & $3.7 \pm 0.7$ & 0.66 \\
\hline Peak aortic PG, mm Hg & $58 \pm 17$ & $60 \pm 20$ & $60 \pm 22$ & $56 \pm 20$ & 0.57 \\
\hline Mean aortic $\mathrm{PG}, \mathrm{mm} \mathrm{Hg}$ & $33 \pm 10$ & $35 \pm 13$ & $32 \pm 13$ & $32 \pm 12$ & 0.32 \\
\hline AVA (equation of continuity), $\mathrm{cm}^{2}$ & $0.84 \pm 0.14$ & $0.78 \pm 0.14$ & $0.76 \pm 0.17$ & $0.77 \pm 0.17$ & $<0.001$ \\
\hline AVA index, $\mathrm{cm}^{2} / \mathrm{m}^{2}$ & $0.57 \pm 0.10$ & $0.53 \pm 0.10$ & $0.54 \pm 0.13$ & $0.56 \pm 0.15$ & 0.06 \\
\hline LV end-diastolic diameter, mm & $44 \pm 6$ & $45 \pm 6$ & $45 \pm 6$ & $45 \pm 5$ & 0.85 \\
\hline LV end-systolic diameter, mm & $27 \pm 5$ & $28 \pm 5$ & $28 \pm 5$ & $30 \pm 5$ & 0.02 \\
\hline LVEF, \% & $69 \pm 8$ & $67 \pm 9$ & $68 \pm 8$ & $65 \pm 8$ & 0.007 \\
\hline IVST in diastole, mm & $11 \pm 2$ & $11 \pm 2$ & $12 \pm 2$ & $11 \pm 3$ & 0.006 \\
\hline PWT in diastole, mm & $10 \pm 2$ & $11 \pm 2$ & $11 \pm 2$ & $10 \pm 3$ & 0.09 \\
\hline LV mass, $\mathrm{g}$ & $166 \pm 51$ & $179 \pm 52$ & $187 \pm 58$ & $176 \pm 59$ & 0.052 \\
\hline $\begin{array}{l}\text { Any combined valvular disease } \\
\text { (moderate or severe) }\end{array}$ & $39(19)$ & $37(39)$ & $19(45)$ & $25(50)$ & $<0.001$ \\
\hline Moderate or severe AR & $23(11)$ & $16(17)$ & $6(14)$ & $15(30)$ & 0.01 \\
\hline Moderate or severe MS & $2(1.0)$ & $6(6.4)$ & $2(4.8)$ & $2(4.0)$ & 0.08 \\
\hline
\end{tabular}


Table 1 Continued

\begin{tabular}{|c|c|c|c|c|c|}
\hline & Group 1 & Group 2 & Group 3 & Group 4 & \multirow[b]{3}{*}{$P$ values } \\
\hline & $B N P<100 \mathrm{pg} / \mathrm{mL}$ & $100 \leq B N P<200 \mathrm{pg} / \mathrm{mL}$ & $200 \leq B N P<300 \mathrm{pg} / \mathrm{mL}$ & $\mathrm{BNP} \geq 300 \mathrm{pg} / \mathrm{mL}$ & \\
\hline & $(n=201)$ & $(n=94)$ & $(n=42)$ & $(n=50)$ & \\
\hline Moderate or severe TR & $14(7.0)$ & $17(18)$ & $8(19)$ & $15(30)$ & $<0.001$ \\
\hline TR pressure gradient $\geq 40 \mathrm{~mm} \mathrm{Hg}$ & $13(6.5)$ & $13(14)$ & $5(12)$ & $14(28)$ & $<0.001$ \\
\hline
\end{tabular}

We presented the categorical variables as number (\%), and the continuous variables as mean $\pm \mathrm{SD}$, or median with IQR.

$A R$, aortic regurgitation; $A V A$, aortic valve area; BMI, body mass index; BNP, B-type natriuretic peptide; $B S A$, body surface area; $C A B G$, coronary artery bypass grafting; IVST, interventricular septum thickness; LV, left ventricular; LVEF, left ventricular ejection fraction; MR, mitral regurgitation; MS, mitral stenosis;

PCl, percutaneous coronary intervention; PG, pressure gradient; PROM, predicted risk of mortality; PWT, posterior wall thickness; STS, Society of Thoracic Surgeons;

$T R$, tricuspid regurgitation; Vmax, peak aortic jet velocity.

recommended as class $2 \mathrm{a}$ indication in patients with asymptomatic severe AS with $\operatorname{Vmax} \geq 5 \mathrm{~m} / \mathrm{s}$ and/or $\mathrm{LVEF}<50 \%$, who were excluded in our analyses. ${ }^{2}$ We previously reported several additional new markers predicting higher risk for AS-related adverse events such as LVEF $50 \%-59 \%,{ }^{18} 4.5 \leq \mathrm{Vmax}<5 \mathrm{~m} / \mathrm{s}^{19}$ and high left ventricular mass index (LVMI). ${ }^{20}$ These new markers as well as high BNP levels are important to identify extremely high-risk patients who would benefit from an initial AVR

\section{Aortic valve-related death or 100\% HF hospitalization}

8

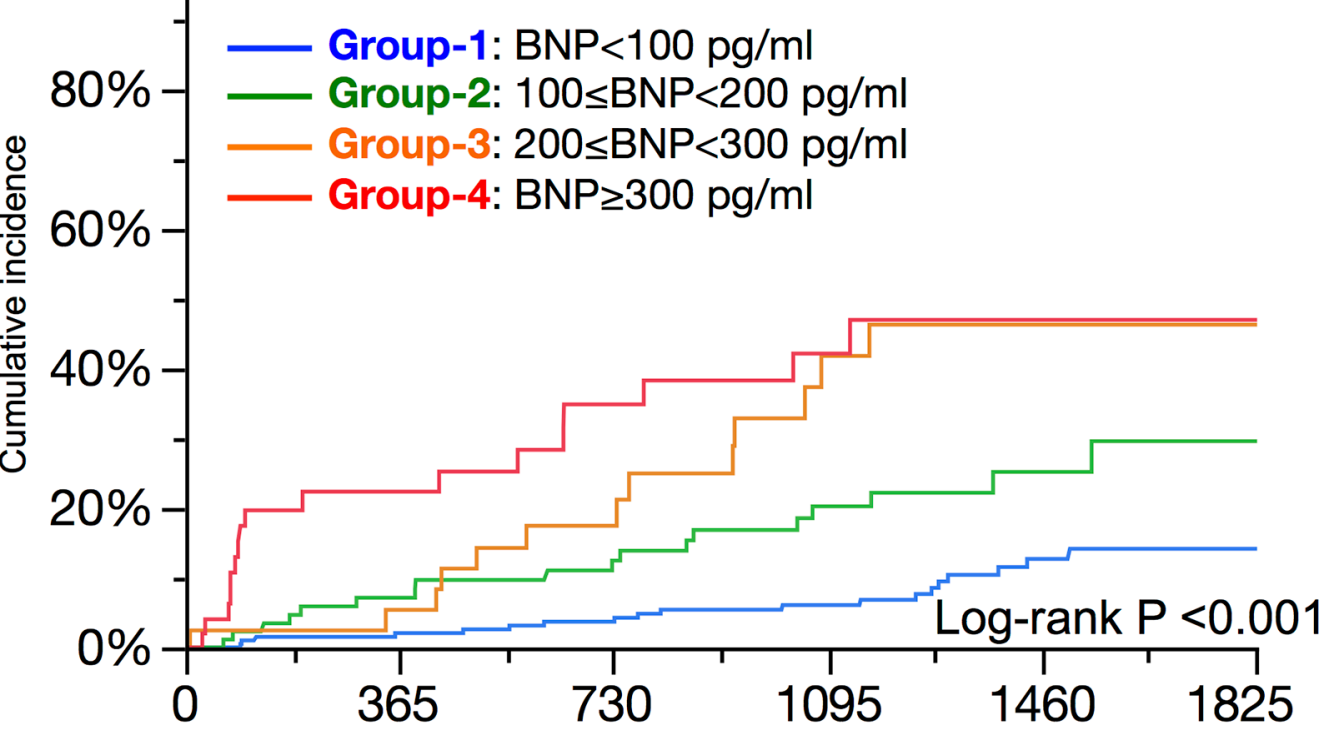

Follow-up Interval (days)

\begin{tabular}{|c|c|c|c|c|c|}
\hline Interval & 0 days & 30 days & 1 year & 3 years & 5 years \\
\hline \multicolumn{6}{|l|}{ Group-1 } \\
\hline $\mathrm{N}$ of patients with event & & 0 & 4 & 11 & 19 \\
\hline $\mathrm{N}$ of patients at risk & 201 & 199 & 184 & 134 & 30 \\
\hline Cumulative incidence & & $0 \%$ & $2.1 \%$ & $6.1 \%$ & $14.2 \%$ \\
\hline \multicolumn{6}{|l|}{ Group-2 } \\
\hline $\mathrm{N}$ of patients with event & & 1 & 17 & 38 & 47 \\
\hline $\mathrm{N}$ of patients at risk & 94 & 92 & 74 & 45 & 9 \\
\hline Cumulative incidence & & $0 \%$ & $7.1 \%$ & $20.2 \%$ & $29.6 \%$ \\
\hline \multicolumn{6}{|l|}{ Group-3 } \\
\hline $\mathrm{N}$ of patients with event & & 1 & 2 & 12 & 13 \\
\hline $\mathrm{N}$ of patients at risk & 42 & 39 & 33 & 14 & 3 \\
\hline Cumulative incidence & & $2.4 \%$ & $5.4 \%$ & $41.8 \%$ & $46.3 \%$ \\
\hline \multicolumn{6}{|l|}{ Group-4 } \\
\hline $\mathrm{N}$ of patients with event & & 1 & 10 & 16 & 17 \\
\hline $\mathrm{N}$ of patients at risk & 50 & 50 & 28 & 16 & 3 \\
\hline Cumulative incidence & & $2.0 \%$ & $22.3 \%$ & $42.1 \%$ & $47.0 \%$ \\
\hline
\end{tabular}

Figure 2 Kaplan-Meier curves for the primary outcome measure according to the baseline BNP levels. The primary outcome measure was defined as a composite of aortic valve-related death or HF hospitalisation. Patients were divided into four groups according to the baseline BNP levels (group 1: $\mathrm{BNP}<100 \mathrm{pg} / \mathrm{mL}$, group 2: $100 \leq \mathrm{BNP}<200 \mathrm{pg} / \mathrm{mL}$, group 3: $200 \leq \mathrm{BNP}<300 \mathrm{pg} / \mathrm{mL}$ and group 4: $\mathrm{BNP}>300 \mathrm{pg} / \mathrm{mL}$ ). BNP, B-type natriuretic peptide; $H F$, heartfailure. 


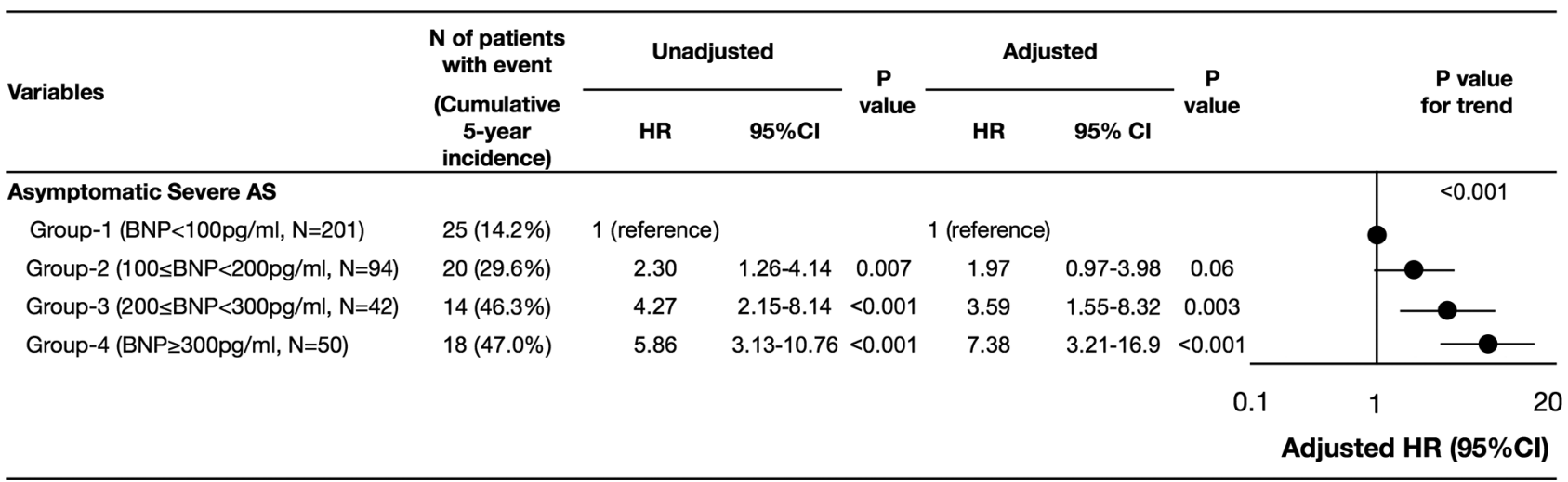

Figure 3 Effects of the baseline BNP levels on the primary outcome measure. The unadjusted and adjusted effects of group 2 (100 $\leq \mathrm{BNP}<200 \mathrm{pg} /$ $\mathrm{mL})$, group $3(200 \leq B N P<300 \mathrm{pg} / \mathrm{mL})$ and group $4(B N P \geq 300 \mathrm{pg} / \mathrm{mL})$ relative to group 1 (reference: $B N P<100 \mathrm{pg} / \mathrm{mL})$ on the composite of aortic valverelated death or HF hospitalisation were analysed. $\mathrm{AS}$, aortic stenosis; BNP, B-type natriuretic peptide; HF, heart failure.

strategy. However, the biggest limitation for these new markers was that even those patients with severe AS with $\mathrm{LVEF} \geq 60 \%$, Vmax $<4.5 \mathrm{~m} / \mathrm{s}$ or normal LVMI still had unacceptably high AS-related adverse event rates. Therefore, these new markers

\begin{tabular}{|c|c|c|c|}
\hline & \multirow{2}{*}{$\begin{array}{l}\text { Number of patients } \\
\text { with event } \\
\text { (Cumulative 5-year } \\
\text { incidence) }\end{array}$} & \multicolumn{2}{|l|}{ Unadjusted } \\
\hline & & HR $(95 \% \mathrm{Cl})$ & $P$ values \\
\hline \multicolumn{4}{|c|}{ All-cause death } \\
\hline Group 1 & $40(23.2 \%)$ & 1 (reference) & \\
\hline Group 2 & $31(39.5 \%)$ & 2.00 (1.24 to 3.19$)$ & 0.005 \\
\hline Group 3 & $22(68.3 \%)$ & 3.46 (2.02 to 5.77$)$ & $<0.001$ \\
\hline Group 4 & $26(56.1 \%)$ & 4.37 (2.62 to 7.16 ) & $<0.001$ \\
\hline \multicolumn{4}{|c|}{ Cardiovascular death } \\
\hline Group 1 & $14(8.0 \%)$ & 1 (reference) & \\
\hline Group 2 & $15(22.9 \%)$ & 2.88 (1.38 to 6.05$)$ & 0.005 \\
\hline Group 3 & $12(44.2 \%)$ & 5.54 (2.51 to 12.04$)$ & $<0.001$ \\
\hline Group 4 & $17(42.1 \%)$ & 8.70 (4.24 to 18.15$)$ & $<0.001$ \\
\hline \multicolumn{4}{|c|}{$\begin{array}{l}\text { Aortic valve-related } \\
\text { death }\end{array}$} \\
\hline Group 1 & $10(6.4 \%)$ & 1 (reference) & \\
\hline Group 2 & $10(18.1 \%)$ & 2.72 (1.11 to 6.65$)$ & 0.03 \\
\hline Group 3 & $7(28.7 \%)$ & 4.70 (1.70 to 12.32$)$ & 0.004 \\
\hline Group 4 & $9(26.5 \%)$ & $6.92(2.72$ to 17.40$)$ & $<0.001$ \\
\hline \multicolumn{4}{|c|}{ Sudden death } \\
\hline Group 1 & $6(3.5 \%)$ & 1 (reference) & \\
\hline Group 2 & $4(4.7 \%)$ & 1.85 (0.47 to 6.53$)$ & 0.36 \\
\hline Group 3 & $1(8.3 \%)$ & 1.20 (0.06 to 7.09$)$ & 0.87 \\
\hline Group 4 & $4(12.1 \%)$ & $5.17(1.29$ to 18.80$)$ & 0.02 \\
\hline \multicolumn{4}{|c|}{ HF hospitalisation } \\
\hline Group 1 & $19(9.5 \%)$ & 1 (reference) & \\
\hline Group 2 & $16(25.7 \%)$ & 2.43 (1.23 to 4.74$)$ & 0.01 \\
\hline Group 3 & $14(46.3 \%)$ & 5.59 (2.73 to 11.17$)$ & $<0.001$ \\
\hline Group 4 & $14(38.3 \%)$ & 5.98 (42.92 to 11.96$)$ & $<0.001$ \\
\hline
\end{tabular}

Number of patients with event was counted through the entire follow-up period, while the cumulative incidence was estimated at 5 year. Aortic valve-related death included aortic procedure-related death, sudden death and death due to heart failure. HF hospitalisation was defined as hospitalisation due to worsening heart failure requiring intravenous drug therapy.

BNP, B-type natriuretic peptide; HF, heart failure. are not appropriate to identify low-risk patients who are suitable for watchful waiting strategy. It is remarkable that the cumulative 1-year incidence of the AS-related adverse events was only $2.1 \%$ in asymptomatic patients with BNP levels of $<100 \mathrm{pg} / \mathrm{mL}$, who might be safely followed with watchful waiting strategy. We could readily and repeatedly measure the BNP levels of patients with severe AS in daily clinical practice. Measurement of the BNP levels in regular intervals might be a good safety monitor in patients with severe AS under watchful waiting.

In patients with asymptomatic severe AS who cannot exercise because of non-cardiac disease, BNP level measurements could serve as a surrogate marker of symptom status. An initial AVR strategy might be a viable option for patients with asymptomatic severe AS with normal LVEF and elevated BNP levels, but a randomised controlled trial is required to confirm this. Collectively, using the BNP levels in combination with AS-related symptoms might aid the prediction of clinical outcomes in patients with severe AS, supporting the recent guideline recommendation (class 2a, level of evidence C) of AVR surgery in patients with asymptomatic severe AS with an elevated BNP level. ${ }^{3}$

\section{LIMITATIONS}

The current study has several limitations. First, we did not assess the serial changes in the BNP levels during the follow-up period, because this study was a retrospective one, and the timing of follow-up laboratory examinations was not predefined. Second, BNP level data were not available for all patients in the registry because of the retrospective nature of the study. Third, the cut-off levels for BNP were arbitrary. Fourth, the data in this study were mainly from an era when TAVI were scarcely used. Finally, this study, as was the case for other previous studies, was affected by the limitations inherent to observational studies. Unmeasured confounders might have influenced the study results, although we conducted an extensive statistical adjustment for potential confounders that might affect BNP levels.

\section{CONCLUSIONS}

Increased BNP level was associated with a higher risk for AS-related adverse events in patients with asymptomatic severe AS with normal LVEF who were not referred for AVR. Asymptomatic patients with BNP levels of $<100 \mathrm{pg} / \mathrm{mL}$ had relatively low event rate, who might be safely followed with watchful waiting strategy. 


\section{Key questions}

\section{What is already known on this subject?}

- There is still a paucity of data regarding risk stratification based on the B-type natriuretic peptide (BNP) level in patients with asymptomatic severe aortic stenosis (AS), because most of the previous studies have included patients with moderate AS.

\section{What might this study add?}

- Patients with asymptomatic severe AS with elevated BNP levels were associated with a higher risk of AS-related adverse events.

- Asymptomatic patients with BNP levels of $<100 \mathrm{pg} / \mathrm{mL}$ had relatively low event rate.

\section{How might this impact on clinical practice?}

- Patients with asymptomatic severe AS with BNP levels of $<100 \mathrm{pg} / \mathrm{mL}$ might be safely followed with watchful waiting strategy.

\section{Author affiliations}

'Department of Cardiology, Mitsubishi Kyoto Hospital, Kyoto, Japan

${ }^{2}$ Department of Cardiovascular Medicine, Kyoto University Graduate School of Medicine, Kyoto, Japan

${ }^{3}$ Department of Clinical Epidemiology, Hyogo College of Medicine, Nishinomiya, Japan

${ }^{4}$ Department of Cardiology, Kokura Memorial Hospital, Kokura, Japan ${ }^{5}$ Division of Cardiology, Shimada Municipal Hospital, Shimada, Japan ${ }^{6}$ Department of Cardiology, Shizuoka City Shizuoka Hospital, Shizuoka, Japan ${ }^{7}$ Department of Cardiovascular Medicine, Kobe City Medical Center General Hospital, Kobe, Japan

${ }^{8}$ Department of Cardiovascular Medicine, Kurashiki Central Hospital, Kurashiki, Japan ${ }^{9}$ Department of Cardiology, Tenri Hospital, Tenri, Japan

${ }^{10}$ Division of Cardiology, Nara Hospital, Kinki University Faculty of Medicine, Ikoma, Japan

${ }^{11}$ Department of Cardiology, Kinki University Hospital, Osakasayama, Japan

${ }^{12}$ Department of Cardiovascular Center, Osaka Red Cross Hospital, Osaka, Japan

${ }^{13}$ Department of Cardiology, Koto Memorial Hospital, Higashiomi, Japan

${ }^{14}$ Department of Cardiology, Shizuoka General Hospital, Shizuoka, Japan

${ }^{15}$ Department of Cardiology, Nishikobe Medical Center, Kobe, Japan

${ }^{16}$ Department of Cardiology, Japanese Red Cross Wakayama Medical Center,

Wakayama, Japan

${ }^{17}$ Department of Cardiology, National Hospital Organization Kyoto Medical Center,

Kyoto, Japan

${ }^{18}$ Cardiovascular Center, The Tazuke Kofukai Medical Research Institute, Kitano

Hospital, Osaka, Japan

${ }^{19}$ Department of Cardiology, Hikone Municipal Hospital, Hikone, Japan

${ }^{20}$ Department of Cardiology, Kansai Electric Power Hospital, Osaka, Japan

${ }^{21}$ Department of Cardiology, Hyogo Prefectural Amagasaki General Medical Center, Amagasaki, Japan

${ }^{22}$ Department of Cardiology, Japanese Red Cross Otsu Hospital, Otsu, Japan

${ }^{23}$ Department of Cardiology, Saiseikai Noe Hospital, Osaka, Japan

${ }^{24}$ Department of Cardiology, Shiga Medical Center for Adults, Moriyama, Japan

${ }^{25}$ Department of Cardiology, Hamamatsu Rosai Hospital, Hamamatsu, Japan

${ }^{26}$ Department of Cardiology, Hirakata Kohsai Hospital, Hirakata, Japan

${ }^{27}$ Department of Cardiovascular Surgery, Kyoto University Graduate School of Medicine, Kyoto, Japan

Acknowledgements The authors appreciate the assistance of the co-investigators at the CURRENT AS Registry.

Contributors TK had full access to all the data in the study and takes responsibility for the integrity of the data and the accuracy of the data analysis. Study concept and design: KN, TM, TT, TK. Acquisition, analysis, or interpretation of data: all authors. Drafting of the manuscript: KN, TM, TK. Critical revision of the manuscript for important intellectual content: all authors. Statistical analysis: KN, TM. Administrative, technical or material support: TK. Study supervision: TM, TK.

Funding This study was funded by Department of Cardiovascular Medicine, Kyoto University Graduate School of Medicine, Kyoto, Japan.

Competing interests None declared.

Patient consent Not required.

Ethics approval The institutional review boards at all 27 participating centers (see the online supplementary appendix) approved the study protocol.

Provenance and peer review Not commissioned; externally peer reviewed.

\section{REFERENCES}

1 lung $B$, Baron G, Butchart EG, et al. A prospective survey of patients with valvular heart disease in Europe: the Euro heart survey on valvular heart disease. Eur Heart $J$ 2003;24:1231-43.

2 Nishimura RA, Otto CM, Bonow RO, et al. 2014 AHA/ACC guideline for the management of patients with valvular heart disease: executive summary: a report of the American College of Cardiology/American Heart Association Task Force on Practice Guidelines. J Am Coll Cardiol 2014;63:2438-88.

3 Baumgartner H, Falk V, Bax JJ, et al. 2017 ESC/EACTS Guidelines for the management of valvular heart disease. Eur Heart J 2017;38:2739-91.

4 Yancy CW, Jessup M, Bozkurt B, et al. 2017 ACC/AHA/HFSA focused update of the 2013 ACCF/AHA guideline for the management of heart failure: a report of the American College of Cardiology/American Heart Association Task Force on Clinical Practice Guidelines and the Heart Failure Society of America. J Am Coll Cardiol 20172017;70:776-803.

5 Ponikowski P, Voors AA, Anker SD, et al. 2016 ESC Guidelines for the diagnosis and treatment of acute and chronic heart failure. Eur Heart J 2016;37:2129-200.

6 Maisel AS, Krishnaswamy P, Nowak RM, et al. Rapid measurement of B-type natriuretic peptide in the emergency diagnosis of heart failure. $N$ Engl J Med 2002;347:161-7.

7 Gerber IL, Stewart RA, Legget ME, et al. Increased plasma natriuretic peptide levels reflect symptom onset in aortic stenosis. Circulation 2003;107:1884-90.

8 Nessmith MG, Fukuta H, Brucks S, et al. Usefulness of an elevated B-type natriuretic peptide in predicting survival in patients with aortic stenosis treated without surgery. Am J Cardiol 2005;96:1445-8.

9 Iwahashi N, Nakatani S, Umemura S, et al. Usefulness of plasma B-type natriuretic peptide in the assessment of disease severity and prediction of outcome after aortic valve replacement in patients with severe aortic stenosis. J Am Soc Echocardiogr 2011;24:984-91.

10 Ben-Dor I, Minha S, Barbash IM, et al. Correlation of brain natriuretic peptide levels in patients with severe aortic stenosis undergoing operative valve replacement or percutaneous transcatheter intervention with clinical, echocardiographic, and hemodynamic factors and prognosis. Am J Cardiol 2013;112:574-9.

11 Lim P, Monin JL, Monchi M, et al. Predictors of outcome in patients with severe aortic stenosis and normal left ventricular function: role of B-type natriuretic peptide. Eur Heart J 2004;25:2048-53.

12 Bergler-Klein J, Klaar U, Heger M, et al. Natriuretic peptides predict symptomfree survival and postoperative outcome in severe aortic stenosis. Circulation 2004; 109:2302-8.

13 Monin JL, Lancellotti P, Monchi M, et al. Risk score for predicting outcome in patients with asymptomatic aortic stenosis. Circulation 2009;120:69-75.

14 Clavel M-A, Malouf J, Michelena HI, et al. B-type natriuretic peptide clinical activation in aortic stenosis. J Am Coll Cardiol 2014;63:2016-25.

15 Kappetein AP, Head SJ, Généreux P, et al. Updated standardized endpoint definitions for transcatheter aortic valve implantation. J Am Coll Cardiol 2012;60:1438-54.

16 Leon MB, Piazza N, Nikolsky E, et al. Standardized endpoint definitions for transcatheter aortic valve implantation clinical trials. J Am Coll Cardiol 2011;57:253-69.

17 Kawai M, Yoshimura M, Harada M, et al. Determination of the B-type natriuretic peptide level as a criterion for abnormalities in Japanese individuals in routine clinical practice: the J-ABS Multi-Center Study (Japan Abnormal BNP Standard). Intern Med 2013;52:171-7.

18 Taniguchi T, Morimoto T, Shiomi H, et al. Prognostic Impact of Left Ventricular Ejection Fraction in Patients With Severe Aortic Stenosis. JACC Cardiovasc Interv 2018;11:145-57.

19 Nakatsuma K, Taniguchi T, Morimoto T, et al. Prognostic impact of peak aortic jet velocity in conservatively managed patients with severe aortic stenosis: an observation from the CURRENT AS Registry. J Am Heart Assoc 2017;6:e005524.

20 Minamino-Muta E, Kato T, Morimoto T, et al. Impact of the left ventricular mass index on the outcomes of severe aortic stenosis. Heart 2017;103:1992-9. 